\title{
The Guinean traditional medicine in the treatment of HIVIAIDS
} AM Baldé*1,2, FB Magassouba1,2, R Barry ${ }^{1,2}$, A Loua ${ }^{2}$, S Traoré ${ }^{1}$, F Mara $^{3}$, O Mara 3 , O Bangoura ${ }^{3}$, A Camara ${ }^{3}$, M Kouyaté ${ }^{3}$, M Kourouma ${ }^{3}$, S Camara ${ }^{3}$, L Bangoura $^{3}$, S Traoré ${ }^{3}$, AK Diallo ${ }^{3}$, A Kinsi Diallo ${ }^{3}$, G Mamy³, G Kolomou ${ }^{3}$, S Mamy ${ }^{3}$, A Dieng ${ }^{4}$, MD Barry ${ }^{5}$, F Soumah ${ }^{5}$, A Traoré ${ }^{5}$, L Pieters 6 , J Totté ${ }^{6}$ and AJ Vlietinck ${ }^{6}$

Address: ${ }^{1}$ Centre de Recherche et de Valorisation des Plantes Médicinales de Dubréka, Guinea, ${ }^{2}$ Département of Pharmacy, University of Conakry, Guinea, ${ }^{3}$ Traditional healers (leaders), Guinea, ${ }^{4}$ Gesellschaft für Technische Zusammenarbeit, Conakry, Guinea, ${ }^{5}$ Comité National de Lutte contre le SIDA (CNLS), Conakry, Guinea and ${ }^{6}$ Department of Pharmaceutical Sciences, University of Antwerp, Belgium

Email: AM Baldé* - bmaliou2002@yahoo.fr

* Corresponding author

from 2006 International Meeting of The Institute of Human Virology

Baltimore, USA. 17-2I November, 2006

Published: 21 December 2006

Retrovirology 2006, 3(Supp| I):P6 doi:I0.II86/I742-4690-3-SI-P6

C 2006 Baldé et al; licensee BioMed Central Ltd.

In Guinea, for the majority of the 8 millions inhabitants, essential medicines remain unavailable and unaffordable. With the high cost of the imported drugs, it is less than $10 \%$ of the urban populations that benefited of these. Consequently, malaria and HIV/AIDS continue to claim innumerable lives over the country. The high cost and scarcity of many essential drugs as well as antiretroviral drugs has led the majority of people living with HIV/AIDS to use traditional herbal treatment for a variety of HIVrelated conditions including opportunistic infections. Such widespread use of traditional medicine by people living with HIV/AIDS along with the role of traditional healers in contributing to AIDS prevention and support may be of interest in view to identify, evaluate and develop safe and effective local treatments for HIVrelated-illnesses. Aiming that, an ethnopharmacological survey (2002-2005) over the country led to the recruitment of 418 traditional healers (36 to 87 years old), all assuming to be able to treat at least one Sexual Transmitted Diseases (STD) such as gonorrhoeae, syphilis, AIDS... From these healers, 370 have already heard about HIV/ AIDS and only 120 have declared to be able to treat specifically "HIV/AIDS". After three educational sessions focused on the prevalence, the contamination, the preven- tion and the treatment of both STD and HIV/AIDS, only 9/120 traditional healers were affirmative in being able to cure the disease. An ethnobotanical study has allowed a collection of 190 traditional recipes containing 218 plants used in the traditional treatment of STD. Of the 190 biologically tested extracts, 11 have shown a moderate in vitro antimicrobial effect against Staphylococcus aureus, Mycobacterium fortuitum, Candida albicans, and Herpes simplex virus. Of the 184 extracts tested for their anti-HIV effect, 12 have shown a moderate activity on both strain of the virus (VIH1 and 2). Bioassay guided fractionation on the most active extract resulted in the isolation of some anti-HIV compounds which are under structural investigations. A therapeutic evaluation of two traditional remedies were done under the auspice of the traditional healers and within their social environment. Significant adverse effects have been observed with one remedy. A slight increase of the CD4/CD8 burden was recorded.

These preliminaries results provide evidence on the presence of biologically active constituents. However, due to the adverse effects, an attention must be paid in their uses. 